\title{
KARAKTERISTIK MULTIMEDIA INTERAKTIF MATA PELAJARAN IPA SMP
}

\author{
I.P. Hendra Eka Geminiawan, I.W. Redhana, P. Prima Juniartina \\ Program Studi S1 Pendidikan IPA \\ Universitas Pendidikan Ganesha \\ Singaraja, Indonesia \\ e-mail: eka.geminiawan@undiksha.ac.id
}

\begin{abstract}
Abstrak
Tujuan penelitian ini adalah untuk mengembangkan karakteristik multimedia interaktif pada mata pelajaran cahaya dan alat optik IPA SMP. Berbagai hasil survei nasional maupun internasional menunjukkan bahwa pencapaian prestasi belajar Indonesia berada di bawah negara-negara tetangga. Faktor utama yang menyebabkan rendahnya capaian prestasi belajar Indonesia adalah kurangnya keterampilan tenaga pendidik dalam pengelolaan pembelajaran. Pemilihan media ICT yang tepat dapat meningkatkan motivasi belajar siswa dan membantu siswa untuk memahami konsep IPA yang diajarkan, sehingga prestasi belajar siswa dapat menigkat. Kualitas pembelajaran memerlukan berbagai upaya untuk mewujudkannya. Upaya tersebut dengan berbagai komponen yang terlibat didalam pembelajaran, salah satu di antaranya adalah dengan pemanfaatan media pembelajaran. Penelitian ini menghasilkan produk multimedia interaktif mata pelajaran cahaya dan alat optik. Karakteristik dari multimedia interaktif yang dihasilkan adalah (1) media menyajikan aspek mikroskopis, makroskopis, dan simbolis, (2) merupakan media pembelajaran interaktif dengan simulasi dua arah, (3) topik yang dimuat adalah cahaya dan alat optik kelas VIII SMP semester 2, (4) multimedia interaktif berisikan dubbing yang dapat memandu siswa ketika mandiri belajar, (5) menyajikan simulasi menjodohkan yang dapat membangun rasa ingin tahu siswa, dan (6) memiliki dua jenis kuis, kuis langsung dan kuis khusus untuk evaluasi.
\end{abstract}

Kata kunci: karakteristik media, multimedia interaktif, pengembangan multimedia interaktif.

\section{Abstract}

The purpose of this research is to develop interactive multimedia characteristic in light subjects and SMP science optical instrument. Various national and international survey results show that the achievement of Indonesia's learning achievement is under the neighboring countries. The main factor causing the low achievement of Indonesia's learning achievement is the lack of skills of educators in the management of learning. Selection of appropriate ICT media can improve students' learning motivation and help students to understand the concept of science that is taught, so that student achievement can be improved. The quality of learning requires various efforts to make it happen. These efforts with various components involved in learning, one of which is with the use of instructional media. This research produces interactive multimedia products light subjects and optical instruments. Characteristics of interactive multimedia are: (1) media presents microscopic, macroscopic, and symbolic aspect, (2) is interactive learning media with two-way simulation, (3) the topic is light and optical instrument of class VIII SMP semester 2, (4) interactive multimedia contains dubbing that can guide students when independent learns, (5) presents matchmaking simulations that can build students' curiosity, and (6) has two types of quizzes, live quizzes and a special quiz for evaluation.

Keywords: characteristics of media, interactive multimedia, development of media. 


\section{PENDAHULUAN}

Perkembangan teknologi dan informasi yang terjadi di abad ke-21 berkembang pesat karena dipicu oleh penemuan dalam bidang rekayasa material elektronika. Pesatnya perkembangan teknologi akan berpengaruh besar pada kebutuhan tenaga kerja. Kompetensi berbasis teknologi menjadi syarat utama untuk melamar pekerjaaan pada era globalisasi ini. Market signal atau persyaratan untuk melamar kerja yang dibutuhkan oleh lapangan pekerjaan, baik pada tingkat lokal, nasional maupun global terus berubah setiap saat. Fenomena ini perlu diantisipasi oleh lembaga pendidikan agar kompetensi siswa kedepannya "compatible" dengan kebutuhan nyata dalam syarat kerja (Arsyad, 2011).

Kompetensi lulusan akan menjadi makin penting artinya apabila dikaitkan dengan era global yang ditandai dengan persaingan bebas di segala bidang kehidupan. Dalam hal ini, siswa perlu dibekali dengan berbagai pengalaman belajar yang berasal dari sumber belajar yang bervariasi. Pesatnya perkembangan produkproduk teknologi modern terutama di bidang teknologi informasi dan komunikasi (TIK) dalam beberapa tahun terakhir dipastikan memberikan dampak luar biasa terhadap persyaratan kerja dan jenis pekerjaan. Hal tersebut menjadikan peserta didik yang akan melanjutkan studi dan memasuki dunia kerja, perlu diberikan pengalaman belajar berbasis TIK.

Kemajuan TIK dan media pembelajaran yang pesat belum dapat dimanfaatkan secara maksimal oleh lembaga pendidikan di Indonesia. Berbagai hasil survei nasional maupun internasional menunjukkan bahwa pencapaian prestasi belajar Indonesia berada di bawah negara-negara tetangga. The TIMSS (Trends in International Mathematics and Science Study) 2011 International Result in Science, yaitu sebuah studi yang mengukur pencapaian hasil belajar IPA siswa di berbagai negara di dunia, menyebutkan bahwa Indonesia menempati posisi 40 dari 45 negara yang ikut serta dalam studi ini. Indonesia juga mengalami penurunan nilai dari 427 pada tahun 2007 menjadi 406 pada tahun 2011. Negara tetangga kita, Singapura, menempati posisi pertama dunia dengan melampaui negara-negara maju lainnya seperti Cina Taipei, Korea, Jepang, Finlandia, Rusia, dan Amerika.

Faktor utama yang menyebabkan rendahnya capaian prestasi belajar Indonesia adalah kurangnya keterampilan tenaga pendidik dalam pengelolaan pembelajaran (Dikti, 2007). Siswa cepat bosan dan lelah berpikir jika guru hanya menggunakan metode belajar yang sama secara terus menerus. Variasi dalam mengajarkan konsep IPA sangat diperlukan oleh siswa. Variasi ini dapat berupa metode, pendekatan, dan media ICT yang digunakan dalam pembelajaran.

Pemilihan media ICT yang tepat dapat meningkatkan motivasi belajar siswa dan membantu siswa untuk memahami konsep IPA yang diajarkan. Guru harus menyadari bahwa setiap siswa memiliki gaya belajarnya masingmasing. Berbagai macam gaya belajar siswa dapat diatasi dengan penggunaan multimedia interaktif yang memuat simulasi, audio, video, animasi, dan gambar. Penggunaan multimedia interaktif dalam proses pembelajaran di kelas dapat meningkatkan hasil belajar siswa secara signifikan dibandingkan dengan penggunaan PowerPoint saja (Lilisari et al., 2016).

Penggunaan multimedia interaktif dapat membantu guru untuk mengkontruksi pengetahuan awal siswa dengan menampilkan fenomena alam sesuai dengan konsep yang sedang dipelajari (Oyedele, 2013). Pembelajaran konstruktivistik menuntut siswa agar mampu mengembangkan pengetahuan sendiri, belajar mandiri, sedangkan guru berperan sebagai fasilitator, mediator, dan manajer dari proses pembelajaran (Tania, L. \& 
Fadiawati, N., 2015). Pembelajaran konstruktivistik bukanlah kegiatan memindahkan pengetahuan dari pengajar kepada peserta didik, melainkan suatu kegiatan yang memungkinkan peserta didik mampu membangun sendiri pengetahuannya. Sebagai fasilitator, guru harus mampu menyediakan berbagai fasilitas belajar agar siswa dengan mudah bisa memperoleh informasi (Prasetyo, 2015).

Kualitas pembelajaran memerlukan berbagai upaya untuk mewujudkannya. Upaya tersebut dengan berbagai komponen yang terlibat didalam pembelajaran, salah satu di antaranya adalah dengan pemanfaatan media pembelajaran. Hasil penelitian Tania menunjukka bahwa penggunaan media dalam proses pembelajaran secara signifikan mampu meningkatkan pencapaian hasil belajar. Di samping itu, metode pembelajaran juga menentukan pencapaian prestasi (Arsyad, 2011).

\section{METODE PENELITIAN}

Penelitian ini menggunakan metode penelitian dan pengembangan (Research and Development). Model pengembangan yang digunakan adalah model penelitian adaptasi dari model pengembangan ADDIE (Analysis, Design, Develop, Implementation, and Evaluate). Tahap analisis meliputi kegiatan analisis kebutuhan dan analisis konsep topik cahaya dan alat optik. Tahap disain dilakukan kegiatan perancangan multimedia dan mengumpulkan bahan materi (simulasi, video, animasi, gambar, dan audio). Tahap selanjutnya adalah pengembangan multimedia memasukkan bahan-bahan ke dalam aplikasi Adobe Animated CC 2017 sesuai dengan rancangan yang telah dibuat.

Data yang diperlukan dalam penelitian ini adalah kualitatif. Data ini didapat dari berbagai sumber yaitu ahli materi, ahli media dan siswa sehingga menghasilkan produk yang valid.

\section{HASIL DAN PEMBAHASAN}

Penelitian ini menghasilkan produk berupa multimedia interaktif mata pelajaran IPA pada topik cahaya dan alat optik. Karakteristik produk merupakan ciri dari produk multimedia interaktif mata pelajaran IPA yang dihasilkan. Ciri tersebut yang akan membedakan multimedia ini dengan media yang lainnya. Beberapa ciri dari multimedia interaktif yang dikembangkan adalah sebagai berikut.

1. Media menyajikan aspek mikroskopis, makroskopis, dan simbolis. Aspek mikroskopis ditunjukkan dengan gambar partikel cahaya dan bagian-bagian mata, aspek makroskopis ditunjukkan dengan gambar cermin, senter, kaca mata, dan alat optik, aspek simbolis ditunjukkan dalam bentuk rumus-rumus pembentukan bayangan dan kekuatan lensa. Simulasi yang menunjukkan ketiga aspek tersebut dapat dikontrol menggunakan tombol navigasi untuk menghentikan dan menjalankan simulasi.

2. Terdapat simulasi yang dapat membangun pengetahuan siswa dengan meng-input sebuah data ke dalam simulasi dan secara langsung simulasi akan memberikan umpan balik berupa benar salah kepada siswa. Proses pembelajaran interaktif ini dapat membangun rasa ingin tahu siswa serta pemahaman yang diperoleh akan diingat lebih lama.

3. Topik yang dimuat adalah cahaya dan alat optik mata pelajaran IPA SMP semester 2 dengan menggunakan pendekatan induktif dan interaktif.

4. Multimedia interaktif ini berisikan dubbing suara yang terdapat di halaman 
materi. Pemberian dubbing dapat mempermudah pengguna saat menggunakan multimedia interaktif dalam belajar mandiri.

5. Terdapat beberapa simulasi menjodohkan yang mana pengguna diharuskan menarik dan menempatkan sebuah bagian ke tempat yang benar. Simulasi ini akan membangun rasa ingin tahu siswa dan memberikan interaksi dua arah oleh media untuk siswa secara langsung.

6. Kuis yang disajikan oleh media ada dua jenis, kuis langsung yang terdapat didalam materi dan kuis khusus setelah materi selesai. Kuis langsung di dalam materi dapat melatih langsung pemahaman yang didapat oleh siswa sebelum melanjutkan ke materi selanjutnya. Kuis khusus berupa soal pilihan ganda yang dapat menampilkan hasil di akhir setelah semua soal terjawab. Guru dapat menggunakan soal tersebut untuk mengevaluasi proses pembelajaran yang telah berlangsung.

\section{SIMPULAN DAN SARAN}

Berdasarkan hasil penelitian pengembangan multimedia interaktif mata pelajaran IPA di SMP ini, maka dapat ditarik kesimpulan sebagai berikut.

1. Penelitian ini menghasilkan produk multimedia interaktif mata pelajaran cahaya dan alat optik. Karakteristik dari multimedia interaktif yang dihasilkan adalah (1) media menyajikan aspek mikroskopis, makroskopis, dan simbolis, (2) merupakan media pembelajaran interaktif dengan simulasi dua arah, (3) topik yang dimuat adalah cahaya dan alat optik kelas VIII SMP semester 2, (4) multimedia interaktif berisikan dubbing yang dapat memandu siswa ketika mandiri belajar, (5) menyajikan simulasi menjodohkan yang dapat membangun rasa ingin tahu siswa, dan (6) memiliki dua jenis kuis, kuis langsung dan kuis khusus untuk evaluasi.

Berdasarkan simpulan yang diuraikan tersebut peneliti memberikan saran agar produk yang dihasilkan dalam penelitian ini digunakan oleh guru untuk mengajarkan konsep IPA khususnya pada topik cahaya dan alat optik.

\section{DAFTAR RUJUKAN}

Arsyad, A. (2011). Media Pembelajaran. Jakarta: Raja Grafindo Persada.

Benson, A., \& Odera, F. (2013). Selection and use of Media in Teaching Kiswahili Language in Secondary Schools in Kenya. International Journal of Information and Communication Technology Research, 3(1), 12-18.

Klentien, U., \& Kamnungwut, W. (2015). The Impact of Using Electronic Media in English Teaching for Elementary and Secondary Students in Thailand. International Journal of Information and Education Technology, 5(8), 582-586.

Liliasari, Supriyanti, S., \& Hana, M. N. (2016). Students ' Creative Thinking Enhancement Using Interactive Multimedia Of Redox Reaction Creative Thinking Enhancement, 30-34. Diakses http://dx.doi.org/10.18269/jpmipa.v21i1.666 pada 25 Oktober 2017.

Oyedele, V., Rwambiwa, J., \& Mamvuto, A. (2013). Using Educational Media and Technology in Teaching and Learning Processes: A Case of Trainee Teachers At Africa University. Academic Research International, 4(1), 292-300.

Peraturan Menteri Pendidikan Nasional Republik IndonesiaNomor 16 Tahun 2007 tentang Standar Kualifikasi Akademik dan Kompetensi Guru, 2007. Jakarta. 
Prasetyo, Z. K. (2015). "Research and Development: Pengembangan Berbasis Penelitian". Makalah disajikan dalam kuliah umum pada Dosen Pembimbing Tesis dan Mahasiswa Magister Pendidikan Sains Program Pascasarjana Universiter Negeri Sebelas Maret. Universitas Sebelas Maret, Surakarta, 14 Juni 2012.

Tania, L. dan Fadiawati, N. (2015). The Development Of Interactivee-Book Based Chemistry Representations Referred To The Curriculum Of 2013. Jurnal Pendidikan IPA Indonesia. Diakses di http://journal.unnes.ac.id/nju/index.php/jpii pada 25 Oktober 2017. 